\title{
Syncope, driving recommendations, and clinical reality: survey of patients
}

\author{
Renke Maas, Rodolfo Ventura, Christina Kretzschmar, Ali Aydin, Andreas Schuchert
}

Syncope is a common clinical condition, ${ }^{1}$ which for obvious reasons constitutes a very drastic form of driving impairment. The legislative and expert panels in most countries have therefore issued laws or guidelines regarding driving and syncope..$^{2-4}$ So far, however, little is known about the impact of driving recommendations on the behaviour of patients or the incidence of traffic crashes.

\section{Methods and results}

All patients referred to us for investigation of syncope who hold a driving licence are routinely given verbal advice on driving by the physician doing the diagnostic work up. From February 1998 until June 2000 we conducted an anonymous survey among these patients. The survey was based on self reporting and consisted of two short structured interviews about history of syncope, driving, and crashes. We did the first interview on the day of head-up tilt table testing, and the second interview took place at the end of the recommended abstinence from driving. After the first interview we followed up all patients for one year for recurrence of syncope and for road crashes. Of 122 consecutive eligible patients $104(85 \%)$ agreed to participate (table).

Three $(2.9 \%, 95 \%$ confidence interval $1.0 \%$ to $8.1 \%)$ of the 104 patients reported that they have ever had a syncope while driving. In one patient this had resulted in a car crash with minor injury; other road users were not affected. After the first syncope only seven $(6.7 \%$, $3.3 \%$ to $13.2 \%$ ) of 104 drivers had immediately stopped driving by themselves and two $(1.9 \%, 0.5 \%$ to $6.7 \%$ ) patients had stopped driving because of recommendations by the referring physicians.

When contacted for the second interview after three to six months, $82(78.8 \%, 70.0 \%$ to $85.6 \%)$ of the patients remembered our advice on driving. However, all 95 patients $(100 \%, 96.1 \%$ to $100 \%)$ who had been driving until they were counselled by us had continued to drive irrespective of any recommendations.

Within the one year follow up syncope recurred in $19(18.3 \%, 12 \%$ to $26.8 \%)$ patients after a median of 59 (range 8-352) days. Syncope resulted in injury in one patient $(1 \%, 0.2 \%$ to $5.2 \%)$, and another patient $(1 \%$, $0.2 \%$ to $5.2 \%)$ had a syncope while driving but no crash.

\section{Comment}

Adherence to driving recommendations was dramatically low among the patients in our survey. The risk of having recurrences while driving was within the range of previous estimates. ${ }^{25}$ As most patients remembered our advice about driving, the advice may not have been convincing enough. But crashes and injuries related to syncope were not convincing either: only four $(9.5 \%$, $3.8 \%$ to $22.1 \%$ ) of 42 patients who had sustained syncope related injuries before referral stopped driving.
Characteristics of patients surveyed $(n=104)$. Values are numbers of patients (percentages, 95\% confidence intervals) unless stated otherwise

\begin{tabular}{lc} 
Characteristics & \multicolumn{1}{c}{ Values } \\
\hline Male sex & $59(56.7,47.1$ to 65.8$)$ \\
\hline Mean (SD) age (years) & $48.0(16.0)$ \\
\hline Median (interquartile range) No of syncopes & $3.0(1-7)$ \\
\hline Disease: & $41(39.4,30.6$ to 49.0$)$ \\
\hline Coronary artery disease & $16(15.4,9.7$ to 23.5$)$ \\
\hline Neurological disease & $6(5.8,2.7$ to 12.0$)$ \\
\hline Stroke or symptomatic cerebrovascular disease & $2(1.9,0.5$ to 6.7$)$ \\
\hline Malformations of the heart & $6(5.8,2.7$ to 12.0$)$ \\
\hline Arrhythmia & $27(26.0,18.5$ to 35.1$)$ \\
\hline Psychiatric disease & $13(12.5,7.5$ to 20.2$)$ \\
\hline Prodromal symptoms & $61(58.7,49.0$ to 67.6$)$ \\
\hline Injury related to syncope & $42(40.4,31.5$ to 50.0$)$ \\
\hline Positive head-up tilt table test & $40(38.5,29.7$ to 48.1$)$ \\
\hline Recurrence of syncope within 12 months & $19(18.3,12.0$ to 26.8$)$ \\
\hline
\end{tabular}

After a first syncope many patients do not seek medical advice until they have recurrences. This implies that many patients are counselled on driving when the period of the highest risk of recurrence has already passed. The European task force guidelines for driving and heart disease state that a person with recurrent syncope should be advised not to drive until a cause has been identified and symptoms are controlled. ${ }^{4}$ This poses a problem not only for the $13-41 \%$ of patients in whom the cause of syncope cannot be established but also for most other patients since the accuracy of risk estimates and the treatment options are rather limited.

Current driving recommendations for patients with syncope may have only limited practical consequences as patients do not adhere to them. Our patients may have been a rather selected group as they were attending a referral centre. However, if confirmed by others, the gap between recommendations and clinical reality that we observed implies that new means need to be developed for the successful implementation of driving guidelines in patients with syncope.

We thank R H Böger for his comments on the final version of the manuscript

Contributors: RM and RV had the original idea for the study, designed the survey, and wrote the first draft. CK, AA, and RM interviewed the patients and analysed the data. AS redrafted the paper for important intellectual content. Gaby Frost was the study nurse responsible for data entry. RM is the guarantor.

Funding: None.

Competing interests: None declared.
Clinical

Pharmacology Unit Department of Pharmacology, Institute of

Experimental and Clinical

Pharmacology and Toxicology, University-Hospital Hamburg-Eppendorf, Martinistrasse 52 Hamburg, Germany Renke Maas

physician

Department of Cardiology, Internal Medicine,

University-Hospital

Hamburg-Eppendorf

physician

Christina

Kretzschmar

physician

Ali Aydin

physician

Andreas Schuchert associate professor of internal medicine and cardiology

Correspondence to: R Maas maas@uke. uni-hamburg.de

BMJ 2003;326:21
Rodolfo Ventura

1 Brignole M, Alboni P, Benditt D, Bergfeldt L, Blanc JJ, Bloch Thomsen PE, et al. Guidelines on management (diagnosis and treatment) of syncope. Eur Heart J 2001;22:1256-306.

2 Olshansky B, Grubb BP. Driving and syncope. In: Syncope:mechanisms and management. Armonk, NY: Futura Publishing Co, 1998.

3 Epstein AE, Miles WM, Benditt DG, Camm JA, Darling EJ, Friedman PL, et al. Personal and public safety issues related to arrhythmias that may affect consciousness: applications for regulation and physician advice Circulation 1996;94:1147-66.

Circulation 1996;94:1147-66.
Petch MC. Driving and heart disease. Eur Heart J 1998;19:1165-77.

5 Sheldon R, Koshman ML. Can patients with neuromediated syncope safely drive motor vehicles? Am J Cardiol 1995;75:955-6.

(Accepted 24 June 2002) 